\title{
Predicting the Surface Quality of Face Milled Aluminium Alloy Using a Multiple Regression Model and Numerical Optimization
}

\author{
K. Simunovic, G. Simunovic, T. Saric \\ Mechanical Engineering Faculty in Slavonski Brod, University of Osijek, Trg I. Brlic-Mazuranic 2, \\ HR 35000 Slavonski Brod, Croatia, ksimun@sfsb.hr, gsimun@sfsb.hr, tsaric@sfsb.hr
}

\begin{abstract}
The surface roughness is a very significant indicator of surface quality. It represents an essential exploitation requirement and influences technological time and costs, i.e. productivity. For that reason, the main objective of this paper is to analyse the influence of face milling cutting parameters (number of revolution, feed rate and depth of cut) on the surface roughness of aluminium alloy. Hence, a statistical (regression) model has been developed to predict the surface roughness by using the methodology of experimental design. Central composite design is chosen for fitting response surface. Also, numerical optimization considering two goals simultaneously (minimum propagation of error and minimum roughness) was performed throughout the experimental region. In this way, the settings of cutting parameters causing the minimum variability in response were determined for the estimated variations of the significant regression factors.
\end{abstract}

Keywords: Surface roughness, face milling, aluminium alloy, experimental design, regression model.

\section{INTRODUCTION}

$S^{3}$ URFACE QUALITY is mostly dependent on the type of manufacturing process and is determined by the function of the given product. Therefore, the required surface quality must already be defined in the design phase of product development, taking into consideration a number of criteria (functionality, costs, aesthetics, etc.). Consequently, many scientific-research projects and scientific papers deal with the modelling of roughness and optimization of the cutting process so that the desired level of surface quality is obtained. The proper selection of cutting parameters is very important to obtain the minimum value of surface roughness and to extend tool life [1], [2]. In this sense, many models have been developed to predict the surface roughness, such as statistical (regression) models and those based on the application of artificial intelligence.

Designed experiments are widely used for the prediction and optimization of the cutting process, with the aim of obtaining a given surface roughness. Rashid et al. [3] developed a mathematical model to predict the surface roughness in face milling. Ozcelik and Bayramoglu [4] developed a statistical model of surface roughness in high speed face milling with cooling, by changing the number of revolutions, feed rate and depth of cut, similar models were developed by the authors Hayajneh [5] and Barkallah [6]. Wang et al. [7] investigated the influence of cutting parameters on the surface roughness of brass using the face milling on a small milling machine. Azuddin and Abdullah [8] also used designed experiments to optimize the surface roughness by varying the cutting parameters and tool diameter in face milling of aluminium. The Taguchi method is a frequently used technique for the process robustness study; it was used by Asilturk and Neseli [9], Yang and Chen [10], Zhang et al. [11] and many other researchers. Many investigators have used the response surface methodology (RSM) for the development of mathematical models of surface roughness and optimization of the cutting process. RSM methodology and face centred central composite design of experiment were used by Lalwani et al. [12] for the optimization of surface roughness. Soleymani and Khorram [13] investigated the optimal cutting parameters in order to reduce the surface roughness and increase the amount of material removed, using RSM methodology and artificial neural networks.

In the paper [14], a model of surface roughness using neural networks and regression modelling is developed. The paper [15] analyses the influence of the depth of cut, feed rate, and number of revolutions on the surface roughness. Dweiri et al. [16] and Palani and Natarajan [17] applied neural networks to model the surface roughness of face CNC milled aluminium. The paper [18] presents a new approach to determine the optimal cutting parameters leading to the minimum surface roughness in face milling of X20Cr13 stainless steel, by integrating artificial neural network (ANN) and harmony search algorithm (HS). The authors [19] describe the application of neural network for the prediction of surface roughness after the roller burnishing. Because of the direct impact on the cost of production and on productivity, the surface roughness investigations are the subject of research in many other papers [20]-[24].

From the previously discussed papers, the following conclusions can be drawn:

- There are some variables of primary interest that can be controlled (feed rate, number of revolutions, depth of cut) and several other factors that cannot be easily controlled (wear of tool, loads, vibrations, properties of material, tool and workpiece, respectively...).

- The researchers are mainly interested in varying the controlled factors by using the designed experiments.

- Central composite designs in the framework of response surface methodology, and independent, as well as Taguchi designed experiments, are widely used.

- The main goals of experimental investigations are modelling, actual prediction of response (by regression models), as well as optimizing a process (by response surface methodology and Taguchi designed experiments). 
- In recent time, the methods of artificial intelligence have been applied (for example neural networks and genetic algorithms) and integrated into or compared with the regression models.

The objective of this paper is to derive a regression model on the basis of measured surface roughness of face milled aluminium alloy, by varying the levels of cutting parameters (number of revolutions of spindle $n$, feed rate $f$ and depth of cut a) using the designed experiment. An experimental investigation has been performed using a low power CNC milling machine. Since the low power milling machines are not often represented in the manufacturing companies, due to reduced productivity, experimental work using them is not common. Consequently, achieving the satisfactory roughness on low power machines is mostly dependent on rich experience of the machine operator.

Therefore, this study should primarily assist in the modelling of surface roughness of aluminium alloy, machined on low power milling machines. Since the small aluminium parts have been widely used in the automotive industry, the results of this paper (i.e. the regression model and added numerical optimization) can be used by the engineers in the automotive industry.

\section{SUBJECT \& METHODS}

The surface roughness is a very important property and, consequently, there are so many methods and equipment to measure it (mechanical, optical, pneumatic, hydraulic and also contact and non-contact [25]). Accordingly, we have stylus profilers, optical profilers, and more sophisticated scanning tunnelling and atomic force microscopes to measure surface roughness. For this investigation a contact stylus profiler is used. Apart from the measuring device, this section is about the material of investigation, equipment for machining and experimental design.

The material of the specimens is the aluminium alloy Al6061 (AlMg1SiCu); the chemical composition is given in Table 1 . The dimensions of aluminium alloy specimens are $70 \times 30 \times 30 \mathrm{~mm}$ (presented in Fig.1.).

Table 1. Chemical composition of aluminium alloy.

\begin{tabular}{|l|l|l|l|l|l|l|l|l|l|}
\hline Element & $\mathrm{Al}$ & $\mathrm{Cr}$ & $\mathrm{Cu}$ & $\mathrm{Fe}$ & $\mathrm{Mg}$ & $\mathrm{Mn}$ & $\mathrm{Si}$ & $\mathrm{Ti}$ & $\mathrm{Zn}$ \\
\hline wt, \% & 97.4 & 0.3 & 0.2 & 0.1 & 1.0 & 0.1 & 0.6 & 0.1 & 0.2 \\
\hline
\end{tabular}

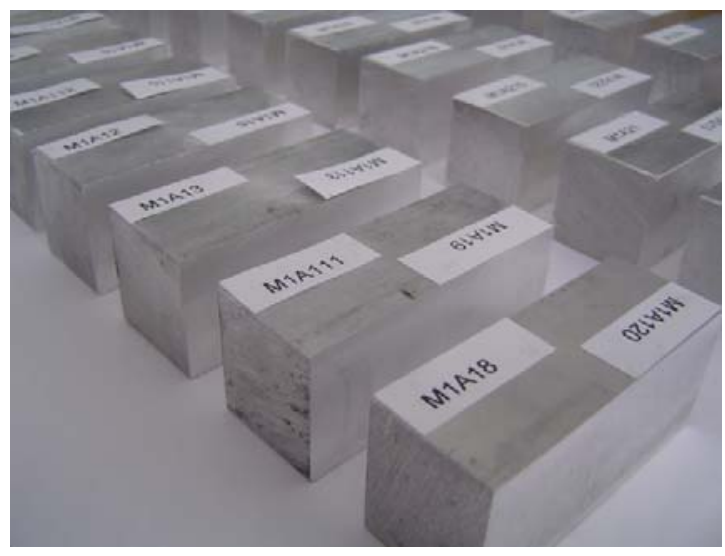

Fig.1. The aluminium alloy specimens.
Machining was performed on a vertical CNC milling machine (characteristics are given in Table 2.), using a high speed steel tool with six cutting edges (given in Fig.2.). The tool is preset and measured before use, on a measuring machine (Fig.3.) so that all the cutting edges are the same height.

Table 2. The characteristics of milling machine.

\begin{tabular}{|l|l|}
\hline Slideway longitudinal (X axis) & $190 \mathrm{~mm}$ \\
\hline Slideway cross (Y axis) & $125 \mathrm{~mm}$ \\
\hline Slideway vertical (Z axis) & $190 \mathrm{~mm}$ \\
\hline Maximal power & $750 \mathrm{~W}$ \\
\hline Maximal spindle speed & $3500 \mathrm{rev} / \mathrm{min}$ \\
\hline Maximal feed rate & $2000 \mathrm{~mm} / \mathrm{min}$ \\
\hline
\end{tabular}

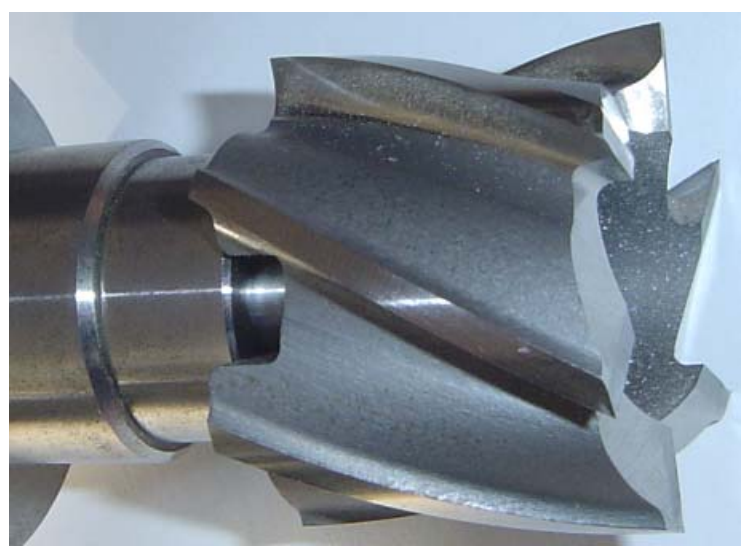

Fig.2. Tool HSS Mayestag $\varnothing 40 \times 32 \times 16$ N3074-Q45.

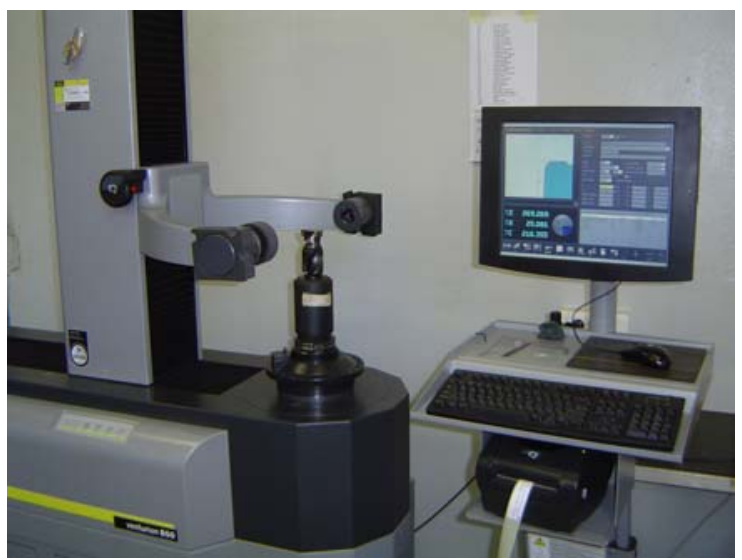

Fig.3. Tool presetter and measuring machine.

The output variable, i.e. surface roughness $R_{a}$, was measured using a device presented in Fig.4. (on the left) whose characteristics are given in Table 3 . This is a contact diamond stylus profiler. For this kind of device, a diamond stylus is moved across the peaks and valleys of the surface to be measured. The main principle is the transformation of mechanical movement of the stylus into an electrical signal which is digitized and processed so the average value of surface roughness $R_{a}$ can be obtained. This equipment is calibrated before use (see the roughness etalon next to the measurement device, Fig.4.). During the measurement, room temperature was $20^{\circ} \mathrm{C}$. 
Table 3. The characteristics of the measuring device.

\begin{tabular}{|l|l|}
\hline Gauge range & $200 \mu \mathrm{m}$ \\
\hline Gauge force & $200 \mathrm{mg}$ \\
\hline Diamond stylus radius & $5 \mu \mathrm{m}$ \\
\hline Cut off value & $0.8 \mathrm{~mm} \pm 15 \%$ \\
\hline Traverse length & $5 \mathrm{~mm}$ \\
\hline Traverse speed & $2 \mathrm{~mm} / \mathrm{sec}$ \\
\hline $\begin{array}{l}\text { Parameters range/resolution: } \\
R_{a}\end{array}$ & $40 \mu \mathrm{m} / 0.01 \mu \mathrm{m}$ \\
\hline
\end{tabular}

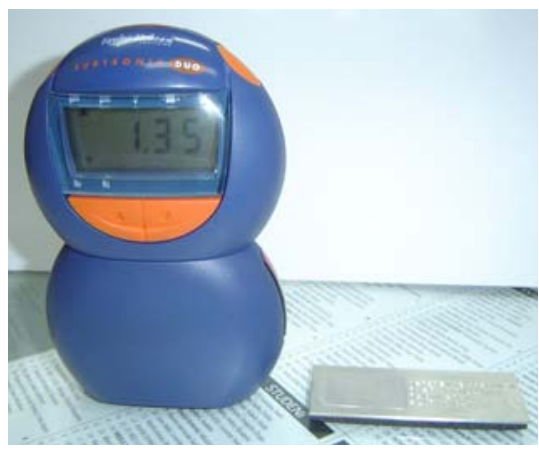

Fig.4. Measuring device and etalon.

The following paragraphs of this chapter are related to the methodology of experimental design. Prior to the main experiment, two pre-experiments were conducted to test the experimental and measurement technique, as well as to define the levels of three quantitative factors. It was concluded that three factors would be varied over the following ranges:

- depth of cut - from 0.3 to $0.8 \mathrm{~mm}$

- feed rate - from 50 to $100 \mathrm{~mm} / \mathrm{min}$

- number of revolutions (spindle speed) - from 500 to $1000 \mathrm{rev} / \mathrm{min}$.

The experimental region, estimated by the conducted preexperiments, is actually the real working region. During the pre-experiments, some of the levels of parameters outside the experimental region caused the effect of the surface pulling, that is, the surface roughness was very high.

The next step was to choose the experimental design. The central composite design (CCD) was chosen. These designs are often used for fitting the second-order model (with quadratic term) in the frame of response surface methodology, but they can be used independently, too. They consist of $2^{k}$ factorial ( $k$ - number of factors) with $n_{f}=2^{k}$ number of factorial runs, $2 k$ axial runs and $n_{c}$ centre runs. For this study, the number of factors $k$ is 3 , so the number of factorial runs $n_{f}$ is 8 , the number of replications in the centre is 6 , and there are 6 axial runs. Therefore, the total number of runs is 20 . The parameter $\alpha$, the position of the axial runs from the centre of the experiment is 1.68179 (according to the $n_{f}^{1 / 4}$ ) [26], and this design is called rotatable CCD.

Some other designs were also considered, such as threelevel factorial $3^{k}$, which is also appropriate for fitting the second-order regression model. However, the implementation of such a design, with at least three replicates, would require a total of $3^{3 * 3}=81$ specimens, which would cause great expenses and can be time consuming. In addition, $3^{k}$ factorial designs are not the most effective way to get quadratic effects; the designs in response surface methodology are a better choice [26]. Furthermore, to estimate the curvature, addition of centre points to a $2^{k}$ factorial design can be a good choice, but sometimes there are not enough runs to estimate the model's regression coefficients. The final decision on the choice of experiment, taking into account all the above mentioned claims, was to conduct the factorial design $2^{3}$ with added centre points and to expand the existing design with six axial runs in case the quadratic term is needed (after the analysis of variance of so obtained model). But, due to the sufficient amount of experimental material and the savings when measuring the output variable or response (roughness) at the remote location, a decision was made to perform the central composite design. It was also decided to implement this design for the safety of a sufficient number of equations to estimate the regression coefficients of the model. This design has a larger number of runs, because of six axial runs.

Table 4. presents five levels of the three factors A, B and $\mathrm{C}$ (factor A: depth of cut $a$, factor B: feed rate $f$ and factor C: number of revolutions $n$ ).

Table 4. The levels of the factors.

\begin{tabular}{|c|c|c|c|c|c|}
\hline Factor & \multicolumn{5}{|c|}{ Levels - coded and (actual) } \\
\hline $\begin{array}{c}\text { A }(a), \\
\mathrm{mm}\end{array}$ & $\begin{array}{c}-1.68179 \\
(0.13)\end{array}$ & $\begin{array}{c}-1 \\
(0.3)\end{array}$ & $\begin{array}{c}0 \\
(0.55)\end{array}$ & $\begin{array}{c}1 \\
(0.8)\end{array}$ & $\begin{array}{c}1.68179 \\
(0.97)\end{array}$ \\
\hline $\mathrm{B}(f)$, & -1.68179 & -1 & 0 & 1 & 1.68179 \\
$\mathrm{~mm} / \mathrm{min}$ & $(32.96)$ & $(50)$ & $(75)$ & $(100)$ & $(117.04)$ \\
\hline $\mathrm{C}(n)$, & -1.68179 & -1 & 0 & 1 & 1.68179 \\
$\mathrm{rev} / \mathrm{min}$ & $(329.55)$ & $(500)$ & $(750)$ & $(1000)$ & $(1170.45)$ \\
\hline
\end{tabular}

The experiment is performed taking into account the basic principles of experimental design. One of the principles is randomization, i.e. runs and allocation of the experimental material are both randomly determined. In this way, the observations (or errors) are independently distributed random variables and some impact of undesirable factors is reduced to a minimum [26]. Another basic principle of the experimental design is performing the experiment in blocks which are used to reduce or eliminate the variability caused by the nuisance factors that can affect the response, but do not concern us directly, as the design factors. For the investigation in this paper, blocking was not used because the machining of the specimens was conducted on a single machine, it was the same operator, measuring the response was carried out by one person, the experiment was performed on the same day and material of specimens was taken from the same batch.

\section{RESUltS}

Table 5. shows the results of the experiment (the last column presents mean or average response of three repeated measurements). The specimens are marked from 1 to 20 according to the standard run order, i.e. conventional schedule for CCD. It means the specimens numbered from 1 to 8 are the points of factorial design, the specimens numbered from 9 to 14 are the axial points and finally, the 
specimens numbered from 15 to 20 are the points at the centre of design (6 replicates). It can be seen that the specimen number 8 (factorial point) was machined first and the specimen number 4 (also factorial point) was the last. So, the randomization principle is fulfilled because the specimens are selected at random.

Table 5. The results of the experiment.

\begin{tabular}{|c|c|c|c|c|c|}
\hline $\begin{array}{l}\text { Standard } \\
\text { Order or } \\
\text { Mark of } \\
\text { specimen }\end{array}$ & Run & $\begin{array}{l}\text { Factor } 1 \\
\text { A: Depth } \\
\text { of cut, } \\
\text { mm }\end{array}$ & $\begin{array}{l}\text { Factor } 2 \\
\text { B: Feed } \\
\text { rate, } \\
\mathrm{mm} / \mathrm{min}\end{array}$ & $\begin{array}{l}\text { Factor } 3 \\
\text { C: Number } \\
\text { of } \\
\text { revolutions, } \\
\text { rev/min }\end{array}$ & $\begin{array}{l}\text { Response- } \\
\text { Roughness } \\
R_{a} \\
\mu \mathrm{m}\end{array}$ \\
\hline 8 & 1 & 0.80 & 100 & 1000 & 5.82 \\
\hline 20 & 2 & 0.55 & 75 & 750 & 5.21 \\
\hline 11 & 3 & 0.55 & 32.96 & 750 & 0.52 \\
\hline 9 & 4 & 0.13 & 75 & 750 & 5.86 \\
\hline 3 & 5 & 0.30 & 100 & 500 & 7.11 \\
\hline 13 & 6 & 0.55 & 75 & 329.55 & 6.11 \\
\hline 2 & 7 & 0.80 & 50 & 500 & 5.14 \\
\hline 6 & 8 & 0.80 & 50 & 1000 & 0.83 \\
\hline 12 & 9 & 0.55 & 117.04 & 750 & 6.97 \\
\hline 10 & 10 & 0.97 & 75 & 750 & 5.76 \\
\hline 18 & 11 & 0.55 & 75 & 750 & 5.85 \\
\hline 5 & 12 & 0.30 & 50 & 1000 & 1.15 \\
\hline 15 & 13 & 0.55 & 75 & 750 & 6.21 \\
\hline 1 & 14 & 0.30 & 50 & 500 & 6.25 \\
\hline 14 & 15 & 0.55 & 75 & 1170.45 & 2.75 \\
\hline 19 & 16 & 0.55 & 75 & 750 & 6.18 \\
\hline 7 & 17 & 0.30 & 100 & 1000 & 6.19 \\
\hline 17 & 18 & 0.55 & 75 & 750 & 5.81 \\
\hline 16 & 19 & 0.55 & 75 & 750 & 5.76 \\
\hline 4 & 20 & 0.80 & 100 & 500 & 6.70 \\
\hline
\end{tabular}

\section{ANALySis OF RESUltS}

Table 6. presents the Analysis of variance for the reduced model. The sum of squares due to the model (regression) equals 76.605 and represents the sum of squared deviations between the predicted values of the regression model and the overall mean of $5.1 \mu \mathrm{m}$. The number of degrees of freedom $d f$ of the regression is 5 (the number of regression terms minus 1 ). The mean square for the regression is 15.321 and $F$ ratio amounts to 76.457 (15.321 divided by 0.2 ) which is higher than the critical $F$ ratio (2.96). Thus, the null hypothesis can be rejected and the alternative one can be accepted. It means that at least one of the regression variables contributes significantly to the model. The model terms B, C, BC, $\mathrm{B}^{2}$ and $\mathrm{C}^{2}$ are significant; $p$ values for the $F$ statistics (198.185; 104.005; 36.220; 33.594 and 13.816) are much smaller than the probability of type I error 0.05 , i.e. the significance level. In other words, $F$ statistics (in brackets above) are greater than the critical one which amounts to 4.6. As previously mentioned, the terms $A, A B$, $\mathrm{AC}$ and $\mathrm{A}^{2}$ are not significant ( $p$ values for the $F$ statistics (1.87; $0.24 ; 0.37$ and 0.20 ) were higher than the probability of type I error 0.05). It is not shown in Table 6.; it is concluded from the analysis of variance for the full model. The testing of Lack of fit is also conducted. The sum of squares of the lack of fit is the weighted sum of squared deviations between the mean response at each level of factor and the corresponding predicted value [26]. For our experiment, this value is not significant, because the $F$ statistic $(0.238 / 0.132=1.805)$ is smaller than the critical one of 4.77 . This is good.
Table 6. Analysis of variance for the reduced model.

\begin{tabular}{|c|c|c|c|c|c|}
\hline Source & $\begin{array}{l}\text { Sum of } \\
\text { Squares, } \\
\text { SS }\end{array}$ & $d f$ & $\begin{array}{l}\text { Mean } \\
\text { Square, } \\
M S\end{array}$ & $\begin{array}{l}F \\
\text { Value }\end{array}$ & $\begin{array}{l}p \text {-value } \\
\text { Prob }>F\end{array}$ \\
\hline Model & 76.605 & 5 & 15.321 & 76.457 & $<0.0001$ \\
\hline B-Feed rate & 39.713 & 1 & 39.713 & 198.185 & $<0.0001$ \\
\hline $\begin{array}{c}\text { C-Number } \\
\text { of revolutions }\end{array}$ & 20.841 & 1 & 20.841 & 104.005 & $<0.0001$ \\
\hline $\mathrm{BC}$ & 7.258 & 1 & 7.258 & 36.220 & $<0.0001$ \\
\hline $\mathrm{B}^{2}$ & 6.732 & 1 & 6.732 & 33.594 & $<0.0001$ \\
\hline $\mathrm{C}^{2}$ & 2.768 & 1 & 2.768 & 13.816 & 0.0023 \\
\hline Residual & 2.805 & 14 & 0.200 & & \\
\hline Lack of Fit & 2.145 & 9 & 0.238 & 1.805 & 0.2671 \\
\hline Pure Error & 0.660 & 5 & 0.132 & & \\
\hline Cor Total & 79.410 & 19 & & & \\
\hline
\end{tabular}

Finally, the addition of centre points to our design allowed us to estimate the pure error because of the replications. The number of degrees of freedom of the pure error is 5 (the number of replicates minus 1 ), and the sum of squares of the pure error amounts to 0.66 . This is the sum of squared deviations between the replicated data at the centre point and the mean value. The sum of squares of the pure error and the sum of squares of the lack of fit are both parts of the sum of squares for residuals. The coefficient of multiple determination $R^{2}$ amounts to 0.965 and presents the portion of explained variability in total variability; it is calculated from (1); SS means Sum of Squares.

$$
R^{2}=\frac{S S_{\text {model }}}{S S_{\text {total }}}=1-\frac{S S_{\text {residual }}}{S S_{\text {total }}}
$$

Adjusted coefficient of determination $R_{a d j}^{2}$ is equal to 0.952 and we can use it because it is not dependent on the number of variables added to the regression model $\left(R_{\text {adj }}^{2}\right.$ is calculated from (2); $m$ is the number of runs and $r$ is the number of regression model terms).

$$
R_{\text {adj }}^{2}=1-\frac{S S_{\text {residual }} /(m-r)}{S S_{\text {total }} /(m-1)}=1-\left(\frac{m-1}{m-r}\right)\left(1-R^{2}\right)
$$

Since the ordinary and adjusted coefficients of determination do not differ significantly, we can conclude that probably non-significant terms are not included in the model. The prediction error sum of squares PRESS is 8.35, and consequently $R^{2}$ for prediction in our experiment amounts to 0.89 . These two values are the measures of predicting the response in a new experiment [26]. The coefficient of variation C.V. \% is the portion of error (i.e. standard deviation) in the mean and is equal to $8.76 \%$. The reduced model in terms of coded factors is presented by (3) (see the coded scale of factors in Table 4.).

$$
\begin{aligned}
& R_{a}=5.87+1.71 \cdot B-1.24 \cdot C+0.95 \cdot B \cdot C-0.68 \cdot B^{2}- \\
& -0.44 \cdot C^{2}
\end{aligned}
$$


The reduced model in terms of natural (actual) factors is presented by (4) (see the actual levels of factors in Table 4.).

$$
\begin{aligned}
& R_{a}=2.987+0.117 \cdot f-0.0059 \cdot n+0.00015 \cdot f \cdot n- \\
& -0.0011 \cdot f^{2}-0.00000697 \cdot n^{2}
\end{aligned}
$$

Fig.5. presents the response surface, where roughness is plotted versus the levels of feed rate and the number of revolutions, with a constant value of depth of cut $(0.55 \mathrm{~mm})$. It can be seen that with higher values of the number of revolutions and lower values of feed rate, the values of roughness are lower, i.e. better. Minimum roughness of $0.86 \mu \mathrm{m}$ is achieved at the high level of number of revolutions and at the low level of feed rate.

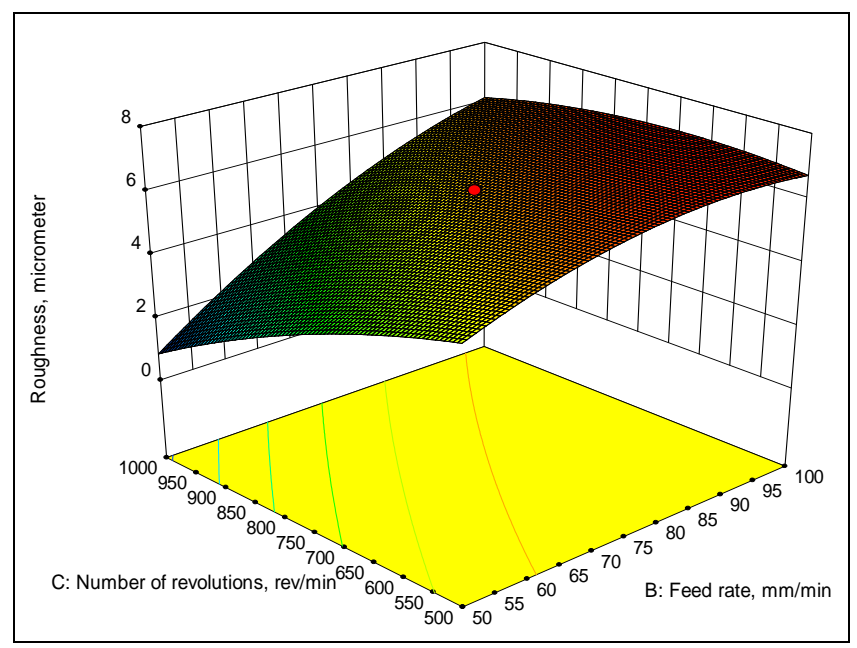

Fig.5. Response surface plot for the regression model.

Model adequacy check is also performed. Normality assumption (the residuals can be described by a normal distribution, that is, the residuals are normally and independently distributed random variables with the mean zero) is checked using the normal probability plot.

From the visual examination of the normal probability plot (Fig.6.), we can see that the cumulative frequency or probability of internally studentized residuals falls approximately along a straight line. There is only one moderate violation which does not affect the analysis of variance. Internally studentized residual is a transformed residual, i.e. the residual divided by the estimated standard deviation of the residual. Internally studentized residuals are normally distributed with the mean zero and unit variance.

Other diagnostics to check independence assumption (plot of residuals in time sequence (run order); plot of residuals versus fitted values and the residuals plotted against input factors) is also done. It indicates that the residuals are structureless; that is, they are unrelated to previously mentioned variables. One of these plots for checking the independence assumption is shown in Fig.7. There is no pattern and there are no residuals greater than 3 standard deviations from zero, so there are no dependency and outliers.

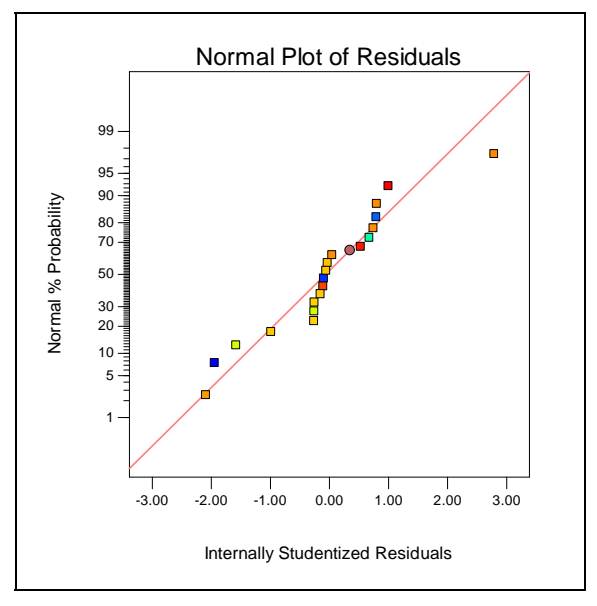

Fig.6. Normal probability plot of residuals.

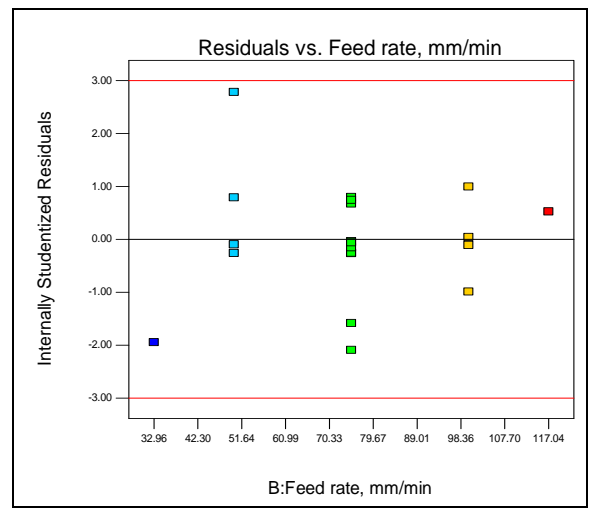

Fig.7. Residuals versus feed rate.

Fig.8. shows the relationship between the predicted values calculated by the model (by using (3) and (4)) and those obtained by the experiment (actual). It can be seen that those values have a very good correlation.

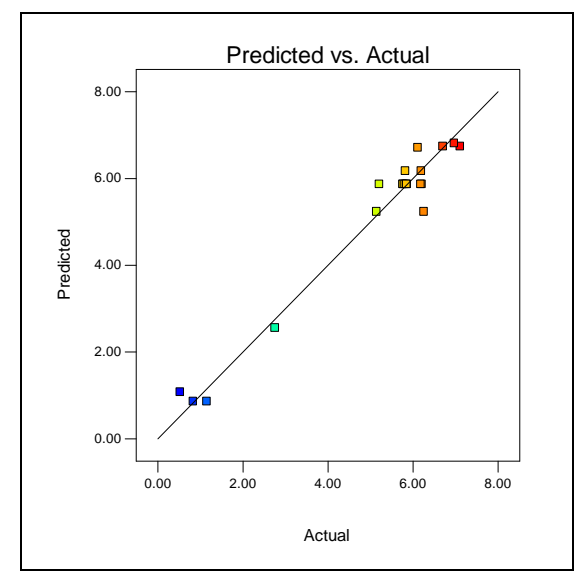

Fig.8. Predicted response (roughness) related to the measured response.

From the perturbation plot of the generated model, shown in Fig.9., we can compare the effect of model factors (B and C) on the response, at the centre point of design space. The coded values of all factor levels at the centre point are 0 (see Table 4.). But it should be mentioned that the effect is 
calculated only for one factor at a time, while all the others are held constant. For example, when the levels of factor $\mathrm{B}$ are changing, the level of factor $\mathrm{C}$ is held constant, i.e. 750 $\mathrm{rev} / \mathrm{min}$ (or coded value 0 ). On the contrary, by changing the levels of factor $\mathrm{C}$, the level of factor B is held constant (75 $\mathrm{mm} / \mathrm{min}$; coded value 0 ). For example, the model values of roughness $R_{a}$ for $\mathrm{B}=0$ (coded value) and $\mathrm{C}=-1 ;-0.5 ; 0 ; 0.5$ and 1 (coded values) are 6.67, 6.38, 5.87, 5.14 and $4.19 \mu \mathrm{m}$, respectively. Having examined the curvatures (of both factors) on the perturbation plot (Fig.9.), a conclusion that the roughness is dependent on the feed rate and number of revolutions can be made. The value of roughness at the centre point calculated by the models in (3) and (4) equals $5.87 \mu \mathrm{m}$, while the average experimental value of five runs at the centre point (runs no. 2, 11, 13, 18 and 19; Table 5.) amounts to $5.84 \mu \mathrm{m}$. There is no significant difference between the model and the experiment.

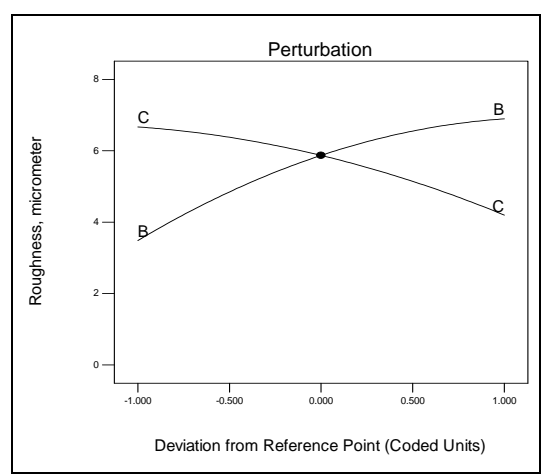

Fig.9. Perturbation plot of the regression model.

Finally, a confirmation run is carried out to test the regression model, that is, to predict new response observation at the point $x_{0}$. A confirmation run is performed with the following levels of factors:

- factor A - coded value of 1.68 or actual value of $0.97 \mathrm{~mm}$

- factor B - coded value of 1 or actual value of $100 \mathrm{~mm} / \mathrm{min}$

- factor C - coded value of -1 or actual value of $500 \mathrm{rev} / \mathrm{min}$.

The predicted value of the response at that point is 6.74 $\mu \mathrm{m}$; it is calculated from the regression model using (3) or (4). According to (5) [26], a 100(1- $\alpha$ ) \% prediction interval for a new observation $y_{0}$ can be calculated.

$$
\begin{aligned}
& \hat{y}\left(x_{0}\right)-t_{\alpha / 2, m-r} \sqrt{\hat{\sigma}^{2}\left(1+x_{0}{ }^{\prime}\left(X^{\prime} X\right)^{-1} x_{0}\right)} \leq y_{0} \leq \hat{y}\left(x_{0}\right)+ \\
& +t_{\alpha / 2, m-r} \sqrt{\hat{\sigma}^{2}\left(1+x_{0}^{\prime}\left(X^{\prime} X\right)^{-1} x_{0}\right)}
\end{aligned}
$$

\section{where:}

$\hat{y}\left(x_{0}\right)$ - the value of response predicted by the regression model at new observation point $x_{0}$

$$
t_{\alpha / 2, m-r} \text { - the value of variable of } t \text { distribution with } m-r
$$

degrees of freedom, for defined probability $\alpha$ of the type I error

$m$ - the number of runs

$r$ - the number of regression model terms $\hat{\sigma}^{2}$ - unbiased estimator of variance

$X$ - the matrix of the levels of the independent variables $X^{\prime}$ - the transpose of the matrix $X$.

The interval within which the new observation would be expected to lie is from 5.63 to $7.85 \mu \mathrm{m}$. The actual measured value of surface roughness in confirmation experiment was $6.85 \mu \mathrm{m}$. It lies within the calculated interval.

\section{NUMERICAL OPTIMIZATION}

This section deals with the numerical multiple optimization in the experimental region, i.e. process robustness study is performed. The main aim of this study is to find the values of significant factors, providing the variability in response as small as possible. Two goals are considered simultaneously:

- minimum propagation of error (POE)

- minimum roughness.

Propagation of error is actually the standard deviation of the variability in response transmitted from the factors [26]. Propagation of error is a function of significant factors. Using the methodology of propagation of error, a new variance model can be obtained for the given standard deviations of significant factors. Consequently, propagation of error plot is constructed as the square root of variance (Fig.10.) according to the following estimated and expected standard deviations of significant model factors:

- factor B, feed rate, $0.5 \mathrm{~mm} / \mathrm{min}$

- factor C, number of revolutions, $2.5 \mathrm{rev} / \mathrm{min}$.

An assumption on deviations of the above mentioned factors is made on the basis of pre-experimental research and practical operator's experience and knowledge in the area of machining.

As seen in Fig.10. (constant value of depth of cut is 0.55 $\mathrm{mm}$ ), variability in response is in the range from 0.448 to $0.454 \mu \mathrm{m}$.

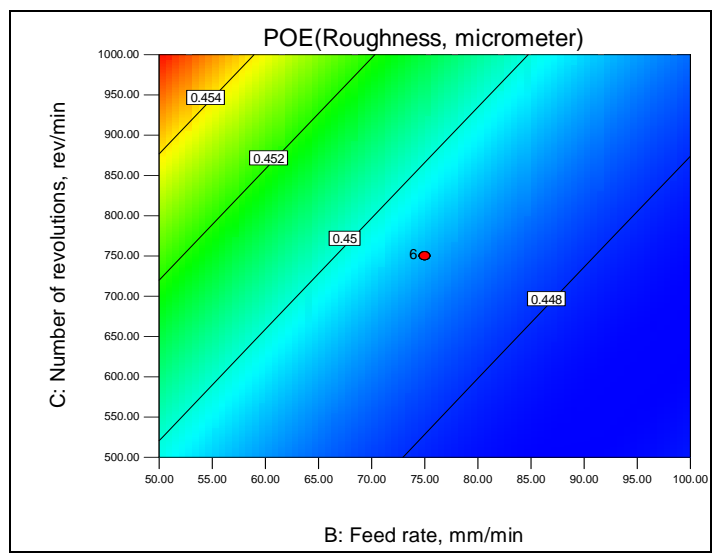

Fig.10. Contour plot of propagation of error as a function of significant factors.

After the calculation of response deviations, a numerical optimization is made for the purpose of searching for the factor values that simultaneously achieve minimum roughness, while minimizing the propagation of error (i.e. variability in response). The best solution is:

- value of propagation of error is $0.45 \mu \mathrm{m}$ 
- value of roughness is $4 \mu \mathrm{m}$

- feed rate is $73.11 \mathrm{~mm} / \mathrm{min}$

- number of revolutions is $1000 \mathrm{rev} / \mathrm{min}$.

Fig.11. shows the contour plot of the regression model (constant value of depth of cut is $0.55 \mathrm{~mm}$ ) with the predicted roughness of $4 \mu \mathrm{m}$ with minimal transmitted variation of $0.45 \mu \mathrm{m}$ (which is slightly high).

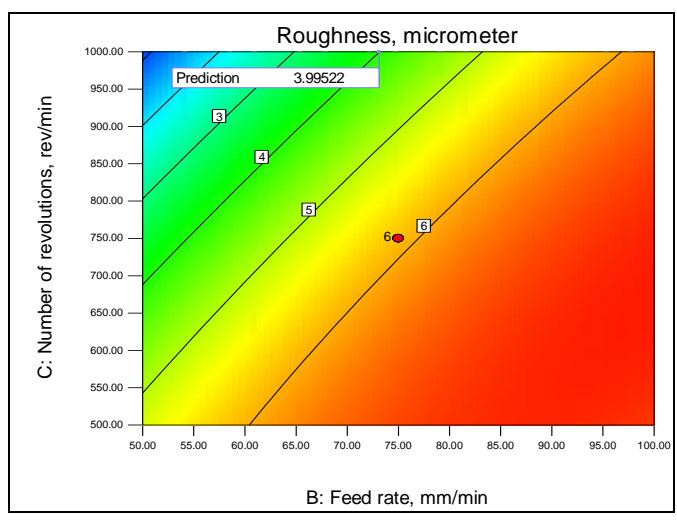

Fig.11. Contour plot of regression model (with marked response of minimum deviation).

\section{CONCLUSIONS}

On the basis of the results of designed CCD experiment conducted to investigate the process of face milling of aluminium alloy, a regression model is obtained. The significant terms in the regression model are as follows: factors B (feed rate $f$ ) and C (number of revolutions $n$ ), as well as the interaction between the feed rate $f$ and number of revolutions $n$. Also, the quadratic terms $\mathrm{B}^{2}$ and $\mathrm{C}^{2}$ are significant. By increasing the values of factor B (feed rate), the roughness increases. On the other hand, by increasing the values of factor $\mathrm{C}$ (number of revolutions), the roughness decreases. The cutting parameter $a$ - depth of cut is not significant in the model, as well as the interaction between the depth of cut $a$ and feed rate $f$, and the depth of cut $a$ and number of revolutions $n$ (the terms $\mathrm{AB}$ and $\mathrm{AC}$ in the model). Also, the quadratic term $\mathrm{A}^{2}$ is not significant.

The coefficient of determination of so obtained model is high (0.965 or 0.952 adjusted) which is very good, as well as the insignificant lack of fit. Therefore, a conclusion can be drawn that the regression model provides a very good fit and can be used to predict roughness throughout the region of experimentation. By the application of the obtained regression model, requirements placed by technical documentation will be more easily and reliably fulfilled. Also, use of the model can affect the reduction in the surface roughness.

The authors also performed numerical optimization throughout the experimental region. Although the minimum calculated roughness amounts to $0.86 \mu \mathrm{m}$, when considering the variability in response at the same time, the roughness which is least sensitive to variability in parameters amounts to $4 \mu \mathrm{m}$.

Further investigation will include more workpiece materials and cutting tools to be compared, as well as use of the techniques of artificial intelligence.

\section{REFERENCES}

[1] Antic, A., Petrovic, P., Zeljkovic, M., Kosec, B., Hodolic, J. (2012). The influence of tool wear on the chip-forming mechanism and tool vibrations. Materiali in tehnologije / Materials and Technology, 46 (3), 279-285.

[2] Tamizharasan, T., Senthil Kumar, N. (2012). Optimization of cutting insert geometry using Deform3D: Numerical simulation and experimental validation. International Journal of Simulation Modeling, 11 (2), 65-76.

[3] Rashid, M.F.F., Gan, S.Y., Muhammad, N.Y. (2009). Mathematical modeling to predict surface roughness in CNC milling. World Academy of Science Engineering and Technology, 53, 393-396.

[4] Ozcelik, B., Bayramoglu, M. (2006). The statistical modeling of surface roughness in high-speed flat end milling. International Journal of Machine Tools \& Manufacture, 46 (12-13), 1395-1402.

[5] Hayajneh, M.T., Tahat, M.S., Bluhm, J. (2007). A study of the effects of machining parameters on the surface roughness in the end-milling process. Jordan Journal of Mechanical and Industrial Engineering, 1 (1), 1-5.

[6] Barkallah, M., Louati, J., Haddar, M. (2012). Evaluation of manufacturing tolerance using a statistical method and experimentation. International Journal of Simulation Modeling, 11 (1), 5-16.

[7] Wang, W., Kweon, S.H., Yang, S.H. (2005). A study on roughness of the micro-end-milled surface produced by a miniatured machine tool. Journal of Materials Processing Technology, 162 (SI), 702-708.

[8] Azuddin, M., Abdullah, W. (2009). A Study on surface roughness and burr formation of Al6061 with different spindle speed and federate for small end milling cutter. International Journal of Integrated Engineering, 1 (1), 7-14.

[9] Asilturk, I., Neseli, S. (2012). Multi response optimisation of CNC turning parameters via Taguchi method-based response surface analysis. Measurement, 45, 785-794.

[10] Yang, J.L., Chen, J.C. (2001). A systematic approach for identifying optimum surface roughness performance in end-milling operations. Journal of Industrial Technology, 17 (2), 1-8.

[11] Zhang, J.Z., Chen, J.C., Kirby, E.D. (2007). Surface roughness optimization in an end-milling operation using Taguchi design method. Journal of Materials Processing Technology, 184 (1-3), 233-239.

[12] Lalwani, D.I., Mehta, N.K., Jain, P.K. (2008). Experimental investigations of cutting parameters influence on cutting forces and surface roughness in finish hard turning of MDN250 steel. Journal of Materials Processing Technology, 206, 167-179.

[13] Soleymani Yazdi, M.R., Khorram, A. (2010). Modeling and optimization of milling process by using RSM and ANN methods. IACSIT International Journal of Engineering and Technology, 2 (5), 474480. 
[14] Rashid, M.F.F., Abdul Lani, M.R. (2010). Surface roughness prediction for CNC milling process using artificial neural network. In Proceedings of the World Congress on Engineering 2010, 30 June - 2 July 2010. Newswood Limited.

[15] Svalina, I., Sabo, K., Simunovic, G. (2011). Machined surface quality prediction models based on moving least squares and moving least absolute deviations methods. International Journal of Advanced Manufacturing Technology, 57 (9-12), 1099-1106.

[16] Dweiri, F., Al-Jarrah, M., Al-Wedyan, H. (2003). Fuzzy surface roughness modeling of CNC down milling of Alumic-79. Journal of Materials Processing Technology, 133 (3), 266-275.

[17] Palani, S., Natarajan, U. (2011). Prediction of surface roughness in CNC end milling by machine vision system using artificial neural network based on 2D Fourier transform. International Journal of Advanced Manufacturing Technology, 54 (9-12), 1033-1042.

[18] Razfar, M.R., Zinati, R.F., Haghshenas, M. (2011). Optimum surface roughness prediction in face milling by using neural network and harmony search algorithm. International Journal of Advanced Manufacturing Technology, 52 (5-8), 487-495.

[19] Stankovic, I., Perinic, M., Jurkovic, Z., Mandic, V., Maricic, S. (2012). Usage of neural network for the prediction of surface roughness after the roller burnishing. Metalurgija, 51 (2), 207-210.
[20] Simunovic, G., Saric, T., Lujic, R. (2009). Surface quality prediction by artificial-neural-networks. Tehnicki vjesnik / Technical Gazette, 16 (2), 43-47.

[21] Vukelic, D., Ostojic, G., Stankovski, S., Lazarevic, M., Tadic, B., Hodolic, J., Simeunovic, N. (2011). Machining fixture assembly/disassembly in RFID environment. Assembly Automation, 31 (1), 62-68.

[22] Cosic, P., Lisjak, D., Antolic, D. (2011). Regression analysis and neural networks as methods for production time estimation. Tehnicki vjesnik / Technical Gazette, 18 (4), 479-484.

[23] Sahoo, P. (2011). Optimization of turning parameters for surface roughness using RSM and GA. Advances in Production Engineering \& Management (APEM), 6 (3), 197-208.

[24] Sadilek, M., Cep, R., Budak, I., Sokovic, M. (2011). Aspects of using tool axis inclination angle. Strojniski vestnik / Journal of Mechanical Engineering, 57 (9), 681-688.

[25] Valicek, J., Drzik, M., Hryniewicz, T., Harnicarova, M., Rokosz, K., Kusnerova, M., Barcova, K., Brazina, D. (2012). Non-contact method for surface roughness measurement after machining. Measurement Science Review, 12 (5), 184-188.

[26] Montgomery, D.C. (2009). Design and Analysis of Experiments $\left(7^{\text {th }}\right.$ ed.). John Wiley and Sons.

Received February 13, 2013. Accepted October 10, 2013. 